\title{
A population-based study of the drug interaction between proton pump inhibitors and clopidogrel
}

\author{
David N. Juurlink MD PhD, Tara Gomes MHSc, Dennis T. Ko MD MSc, Paul E. Szmitko MD, \\ Peter C. Austin PhD, Jack V. Tu MD PhD, David A. Henry MD, Alex Kopp BA, \\ Muhammad M. Mamdani PharmD MPH
}

Published at www.cmaj.ca on Jan. 28, 2009.

$\infty \infty$

See related commentary by Lau and Gurbel, page 699

\section{ABSTRACT}

Background: Most proton pump inhibitors inhibit the bioactivation of clopidogrel to its active metabolite. The clinical significance of this drug interaction is unknown.

Methods: We conducted a population-based nested case-control study among patients aged 66 years or older who commenced clopidogrel between Apr. 1, 2002, and Dec. 31, 2007, following hospital discharge after treatment of acute myocardial infarction. The cases in our study were those readmitted with acute myocardial infarction within 90 days after discharge. We performed a secondary analysis considering events within 1 year. Event-free controls (at a ratio of 3:1) were matched to cases on age, percutaneous coronary intervention and a validated risk score. We categorized exposure to proton pump inhibitors before the index date as current (within 30 days), previous (31-90 days) or remote (91180 days).

Results: Among 13636 patients prescribed clopidogrel following acute myocardial infarction, we identified 734 cases readmitted with myocardial infarction and 2057 controls. After extensive multivariable adjustment, current use of proton pump inhibitors was associated with an increased risk of reinfarction (adjusted odds ratio [OR] $1.27,95 \%$ confidence interval [CI] 1.03-1.57). We found no association with more distant exposure to proton pump inhibitors or in multiple sensitivity analyses. In a stratified analysis, pantoprazole, which does not inhibit cytochrome P450 2C19, had no association with readmission for myocardial infarction (adjusted OR 1.02, 95\% Cl 0.70-1.47).

Interpretation: Among patients receiving clopidogrel following acute myocardial infarction, concomitant therapy with proton pump inhibitors other than pantoprazole was associated with a loss of the beneficial effects of clopidogrel and an increased risk of reinfarction.

Une version française de ce résumé est disponible à l'adresse www.cmaj.ca/cgi/content/full/180/7/713/DC1

CMAJ 2009;180(7):713-8
$\mathrm{P}$ latelet activation and aggregation are key elements of the pathogenesis of acute coronary syndromes. Drugs that impair platelet function are an important part of treatment for patients with ischemic heart disease. Compared with acetylsalicylic acid (ASA) alone, the combination of clopidogrel and ASA significantly reduces the incidence of recurrent coronary events following acute myocardial infarction. ${ }^{1}$ The effectiveness of clopidogrel is underscored by evidence suggesting that delays in clopidogrel treatment, restricted access to the drug and premature cessation of therapy are associated with adverse cardiovascular outcomes. ${ }^{2-5}$

Clopidogrel is a prodrug that is converted in the liver to an active thiol metabolite, which irreversibly inhibits the platelet $\mathrm{P} 2 \mathrm{Y}_{12}$ adenosine diphosphate receptor. ${ }^{6,7}$ This bioactivation is mediated by hepatic cytochrome P450 isoenzymes, with cytochrome $\mathrm{P} 4502 \mathrm{C} 19$ playing a major role. ${ }^{8}$ The activity of cytochrome P450 2C19 dramatically influences the antiplatelet effect of clopidogrel. Patients with loss-of-function polymorphisms have lower levels of the active metabolite of clopidogrel, diminished platelet inhibition during clopidogrel treatment and an increased risk of cardiovascular events relative to those without such polymorphisms. ${ }^{9,10}$

Given the important role of cytochrome P450 2C19 in the bioactivation of clopidogrel, drugs that inhibit this enzyme may reduce the antiplatelet effect of clopidogrel. Proton pump inhibitors are among the most widely prescribed medications worldwide, with more than 12.4 million prescriptions issued in Canada in 2004. ${ }^{11}$ Emerging evidence suggests that some proton pump inhibitors can inhibit cytochrome P450 2C19, possibly altering clopidogrel's pharmacokinetics and potentially leading to an increased risk of adverse cardiac outcomes. ${ }^{12-15}$ Among highrisk angioplasty patients treated with ASA and clopidogrel, use of omeprazole significantly reduced the antiplatelet activity of clopidogrel. ${ }^{14}$ In a series of patients taking clopidogrel, the risk

From the Department of Medicine (Juurlink, Ko, Tu), Sunnybrook Health Sciences Centre, Toronto, Ont.; the Institute for Clinical Evaluative Sciences (Juurlink, Gomes, Ko, Austin, Tu, Henry, Kopp, Mamdani), Toronto, Ont. the Department of Medicine (Szmitko, Mamdani), St. Michael's Hospital, Toronto, Ont.; and the Department of Medicine (Juurlink, Ko, Tu, Henry, Mamdani), the Department of Health Policy, Management and Evaluation (Austin, Henry) and the Dalla Lana School of Public Health (Austin), University of Toronto, Toronto, Ont. 
of acute myocardial infarction was more than $300 \%$ higher among those who were highly adherent to proton pump inhibitors than among those not taking proton pump inhibitors. ${ }^{16}$ However, these studies included relatively few patients and had limited ability to adjust for potential confounders.

Recently published guidelines recommend proton pump inhibitor therapy for the majority of patients treated with ASA after acute myocardial infarction, many of whom will also take clopidogrel..$^{17}$ Consequently, it is probable that millions of patients worldwide will receive combination therapy with a proton pump inhibitor and clopidogrel. However, the clinical significance of the potential interaction between these drugs is unclear. We sought to characterize whether the concomitant use of a proton pump inhibitor with clopidogrel was associated with adverse outcomes among older patients discharged from hospital after acute myocardial infarction.

\section{Methods}

\section{Setting}

We conducted a population-based nested case-control study among Ontario residents aged 66 years or older who were discharged from hospital between Apr. 1, 2002, and Dec. 31, 2007, after treatment for acute myocardial infarction. These individuals had universal access to hospital care, physicians' services and prescription drug coverage. The study was approved by the Research Ethics Board of Sunnybrook Health Sciences Centre.

\section{Data sources}

We examined the computerized prescription records of the Ontario Public Drug Program, which contains comprehensive records of prescription medications dispensed to Ontario residents 65 years of age or older. We identified hospital admissions using the Canadian Institute for Health Information Discharge Abstract Database, which contains detailed diagnostic and procedural information about hospital admissions. We used the Ontario Health Insurance Plan database to identify claims for inpatient and outpatient physician services. We obtained basic demographic information, including date of death, from the Registered Persons Database, which contains a unique entry for each Ontario resident who has ever received a health card. Researchers routinely use these databases to study drug safety, ${ }^{18-20}$ including the clinical consequences of drug-drug interactions. ${ }^{21-23}$ We linked the databases in an anonymous fashion using encrypted 10-digit health-card numbers.

\section{Identification of patients and outcomes}

The study design is outlined in Figure 1. We established a cohort of patients aged 66 years or older who filled a prescription for clopidogrel within 3 days after hospital discharge following treatment for acute myocardial infarction. The date of discharge from hospital served as the date of cohort entry. We excluded patients who had received clopidogrel, ticlopidine or dipyridamole in the year before admission to hospital. We also excluded patients in long-term care facilities and those who received, within 90 days before or after the index date, proton pump inhibitor combination products used to eradicate Helicobacter pylori.

We followed patients who were receiving clopidogrel for a maximum of 90 days after hospital discharge or until readmission because of acute myocardial infarction. We identified patients with continuous use of clopidogrel using an adherence algorithm, which included patients with prescription refills of the drug at intervals not exceeding 1.2 times the number of days' supply of the preceding prescription. We identified hospital admissions using codes from the International Classification of Disease and Related Health Problems, 10th revision, for acute myocardial infarction (I21, I22). We designated the index date as the date of hospital readmission with acute myocardial infarction. For patients who had multiple readmissions with acute myocardial infarction during the study period, we considered only the first readmission.

We defined cases as patients who died or were readmitted for myocardial infarction within 90 days after the initial hospital discharge. We used random sampling with replacement ${ }^{24}$ from the

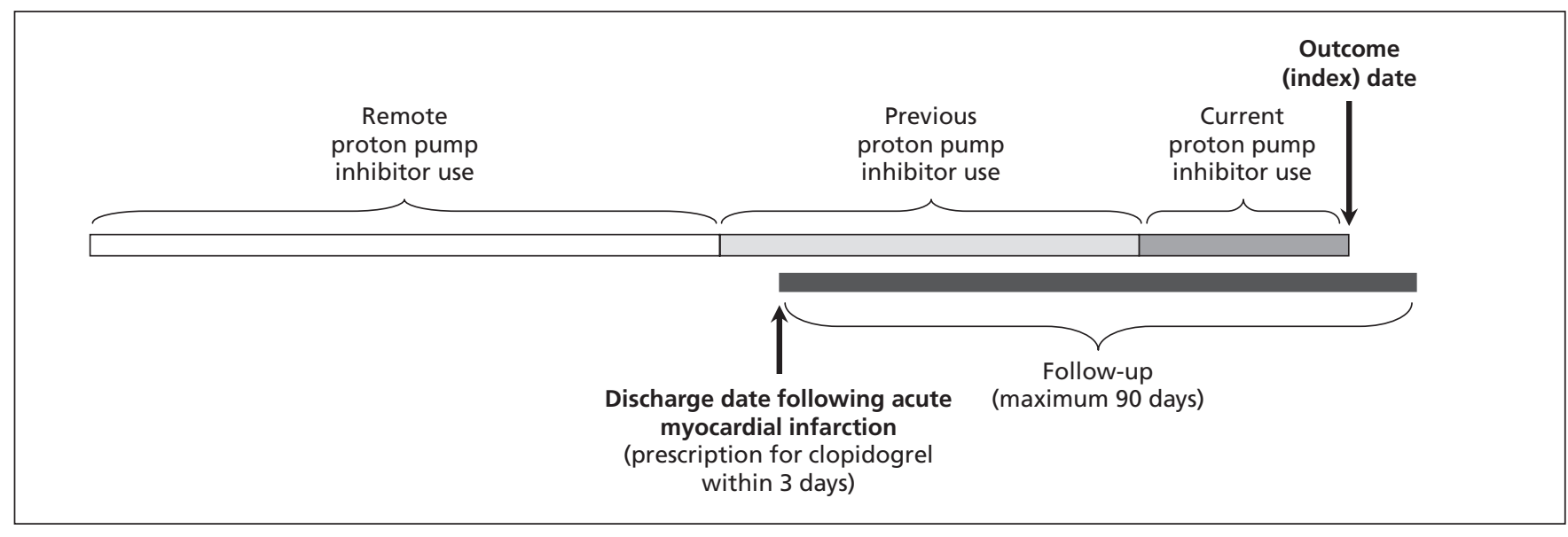

Figure 1: Study design. The solid black line indicates the period following hospital discharge after treatment of acute myocardial infarction. We excluded patients who did not receive a prescription for clopidogrel within 3 days of the discharge date (upward arrow). Among the remaining patients, cases were those readmitted because of myocardial infarction within 90 days after discharge. We attempted to identify 3 matched controls, with no myocardial infarction before the same date (the index date, indicated by downward arrow) for each case. Use of proton pump inhibitors before the index date was categorized as current (within 30 days), previous (31-90 days) or remote (91-180 days). 
same cohort of patients to identify the controls. These individuals were at risk but were not readmitted because of myocardial infarction before the index date. Controls were matched to cases on age (born within 3 years), receipt of percutaneous coronary intervention in hospital (defined as Canadian Classification of Procedure codes 1IJ50 or 1IJ57), date of hospital discharge (within 4 days) and predicted probability of short-term mortality (within 0.05 of that of the corresponding case), determined using a previously validated cardiac risk prediction model. ${ }^{25}$ When the number of controls who could be matched to a case was fewer than 3, we used only those controls and did not alter the matching algorithm.

\section{Exposure to proton pump inhibitors}

We used prescription records to ascertain exposure to proton pump inhibitors during clopidogrel therapy. We categorized use of proton pump inhibitors according to the most proximate prescription as either current (within 30 days before the index date), previous (31-90 days before the index date) or remote (91-180 days before the index date). We reasoned that a causal association between use of a proton pump inhibitor and recurrent myocardial infarction would manifest attenuating effects with more distant exposures.

\section{Statistical analysis}

We used conditional logistic regression to estimate the odds ratio (OR) for the association between reinfarction and exposure to a proton pump inhibitor, using as the reference group patients with no prescription for a proton pump inhibitor in the previous year. We adjusted for age, sex, income quintile (estimated from the residential postal code), Charlson comorbidity index, ${ }^{26}$ length of stay in hospital during the first admission for myocardial infarction, and 9 medical conditions previously shown to correlate with short-term mortality following acute myocardial infarction and identified at the index hospital admission (diabetes with complications, dysrhythmias, pulmonary edema, cardiogenic shock, acute renal insufficiency, chronic renal insufficiency, congestive heart failure and cerebrovascular disease. $)^{25} \mathrm{We}$ also adjusted for use of other commonly used cardiovascular medications, other cytochrome P450 2C19 inhibitors or inducers, and other cytochrome P450 3A4 inhibitors or inducers ${ }^{27}$ (Appendix 1, available at www.cmaj.ca/cgi/content/full/cmaj
.082001/DC1) between hospital discharge and the reference date. In the secondary analysis examining use of histamine $\mathrm{H}_{2}$ receptor antagonists, we also adjusted for exposure to proton pump inhibitors between hospital discharge and the index date.

We conducted several additional analyses to test the robustness of our findings. We altered the definition of "current use" to include any prescription for a proton pump inhibitor

Table 1: Characteristics of study patients

\begin{tabular}{|c|c|c|c|}
\hline \multirow[b]{2}{*}{ Variable } & \multicolumn{2}{|c|}{ Group; no. (\%) of patients* } & \multirow[b]{2}{*}{$p$ value } \\
\hline & $\begin{array}{c}\text { Cases } \\
n=734\end{array}$ & $\begin{array}{l}\text { Controls } \\
n=2057\end{array}$ & \\
\hline \multicolumn{4}{|l|}{ Age, yr } \\
\hline Median (interquartile range) & $77(72-83)$ & $77(72-83)$ & 0.34 \\
\hline $66-75$ & $294(40.1)$ & $839(40.8)$ & 0.73 \\
\hline $76-84$ & $328(44.7)$ & $947(46.0)$ & 0.53 \\
\hline$\geq 85$ & $112(15.3)$ & $271(13.2)$ & 0.16 \\
\hline Male sex & $384(52.3)$ & $1133(55.1)$ & 0.20 \\
\hline Length of stay, median (interquartile range) & $6 \quad(4-9)$ & $6 \quad(4-8)$ & 0.06 \\
\hline $\begin{array}{l}\text { Percutaneous coronary intervention } \\
\text { during index admission }\end{array}$ & $103(14.0)$ & $279(13.6)$ & 0.75 \\
\hline \multicolumn{4}{|l|}{ Comorbidity during index admission } \\
\hline Acute renal insufficiency & $45 \quad(6.1)$ & 67 (3.3) & $<0.001$ \\
\hline Chronic renal insufficiency & $32 \quad(4.4)$ & $74 \quad(3.6)$ & 0.35 \\
\hline Congestive heart failure & $203(27.7)$ & $371(18.0)$ & $<0.001$ \\
\hline Shock & $8 \quad(1.1)$ & $13(0.6)$ & 0.22 \\
\hline Cancer & $23 \quad(3.1)$ & $42(2.0)$ & 0.09 \\
\hline Cerebrovascular disease & $19(2.6)$ & $43(2.1)$ & 0.43 \\
\hline Diabetes mellitus with complications & $208(28.3)$ & 409 (19.9) & $<0.001$ \\
\hline Cardiac dysrhythmias & $103(14.0)$ & $278(13.5)$ & 0.73 \\
\hline Pulmonary edema & $6 \quad(0.8)$ & $17 \quad(0.8)$ & 0.98 \\
\hline \multicolumn{4}{|l|}{ Medication use during follow-upt } \\
\hline Cytochrome P450 2C19 inducer & $28 \quad(3.8)$ & $57(2.8)$ & 0.16 \\
\hline Cytochrome P450 2C19 inhibitor & $8 \quad(1.1)$ & $15 \quad(0.7)$ & 0.35 \\
\hline Cytochrome P450 3A4 inducer & $6 \quad(0.8)$ & $15(0.7)$ & 0.81 \\
\hline Cytochrome P450 3A4 inhibitor & $66 \quad(9.0)$ & $168(8.2)$ & 0.49 \\
\hline \multicolumn{4}{|l|}{ Other medications } \\
\hline Angiotensin-converting-enzyme inhibitor & $419(57.1)$ & $1350(65.6)$ & $<0.001$ \\
\hline Angiotensin-receptor antagonist & $55 \quad(7.5)$ & $163(7.9)$ & 0.71 \\
\hline Acetylsalicylic acidł & $52(7.1)$ & $182(8.8)$ & 0.14 \\
\hline$\beta$-Adrenergic antagonist & $515(70.2)$ & $1530(74.4)$ & 0.027 \\
\hline Calcium-channel antagonist & $146(19.9)$ & $331(16.1)$ & 0.019 \\
\hline Digoxin & $37 \quad(5.0)$ & $73 \quad(3.5)$ & 0.08 \\
\hline Spironolactone & $42 \quad(5.7)$ & $91 \quad(4.4)$ & 0.16 \\
\hline Statin & $527(71.8)$ & $1593(77.4)$ & 0.002 \\
\hline Thiazide diuretic & $58 \quad(7.9)$ & $144(7.0)$ & 0.42 \\
\hline Other diuretic, including loop agent & $229(31.2)$ & $474(23.0)$ & $<0.001$ \\
\hline Nonsteroidal anti-inflammatory drug & $17 \quad(2.3)$ & $56 \quad(2.7)$ & 0.55 \\
\hline
\end{tabular}

*Unless indicated otherwise.

tSee Appendix 1 (www.cmaj.ca/cgi/content/full/cmaj.082001/DC1) for a list of the drugs in each group. ¥Nonprescription use of acetylsalicylic acid could not be ascertained. 
between hospital discharge and the index date, and we conducted analyses of recurrent myocardial infarction and death within 1 year of hospital discharge. We examined use of the histamine $\mathrm{H}_{2}$-receptor antagonists ranitidine, famotidine and nizatidine as a tracer exposure. These drugs have clinical indications similar to those of proton pump inhibitors, yet they do not inhibit cytochrome P450 2C19. To test the specificity of our primary findings, we replicated our analysis in a cohort of patients who did not receive a prescription for clopidogrel within 90 days of discharge following acute myocardial infarction. Finally, we conducted a stratified analysis of the risk of recurrent myocardial infarction during treatment with pantoprazole or with other proton pump inhibitors. Pantoprazole does not inhibit cytochrome P450 2C19 and therefore should not interfere with the metabolic activation of clopidogrel, whereas other proton pump inhibitors or their primary metabolites do inhibit cytochrome P450 2C19 and can be expected to attenuate clopidogrel's beneficial effects. ${ }^{13}$

\section{Results}

Over the 69-month study period, we identified 13636 patients aged 66 years or older who filled a prescription for clopidogrel within 3 days following hospital discharge after treatment of acute myocardial infarction. The median age of these patients was 76 (interquartile range 71-81) years; 7579 (55.6\%) were men. The median length of stay during this admission was 5 days (interquartile range 4-8 days). A total of 4022 patients
(29.5\%) underwent percutaneous coronary intervention. Concomitant prescribing of proton pump inhibitors following discharge was exceedingly common, with 2682 (19.7\%) patients receiving a proton pump inhibitor within 30 days of discharge and $4224(31.0 \%)$ receiving a prescription within 90 days.

From this cohort, we identified 782 patients who were readmitted because of acute myocardial infarction within 90 days after discharge. Of these, 734 (93.9\%) were matched to at least 1 control. The characteristics of cases and controls are shown in Table 1. As expected, cases were more likely than controls to have had several comorbidities during their index admission, including heart failure, diabetes and renal insufficiency.

In the primary analysis, after extensive multivariable adjustment, we found a significant association between readmission because of myocardial infarction and current use of a proton pump inhibitor (adjusted OR 1.27, 95\% confidence interval [CI] 1.03-1.57) but not with earlier use of these drugs. Our findings did not change appreciably when we redefined use of a proton pump inhibitor as a prescription between hospital discharge and the date of readmission, or when we included admission up to 1 year after the date of discharge (Figure 2). As expected, we found no association between recurrent myocardial infarction and use of histamine $\mathrm{H}_{2}$-receptor antagonists, and no such association among patients not treated with clopidogrel (Figure 2). In the stratified analysis of the type of proton pump inhibitor used, pantoprazole was not associated with recurrent myocardial infarction among patients receiving clopidogrel, as predicted by the observation that pantoprazole does

\begin{tabular}{|c|c|c|c|}
\hline Analysis* & $\begin{array}{c}\text { Cases } \\
\mathrm{n} / \mathrm{N}\end{array}$ & $\begin{array}{l}\text { Controls } \\
\mathrm{n} / \mathrm{N}\end{array}$ & $\begin{array}{l}\text { Odds ratio } \\
(95 \% \mathrm{Cl})\end{array}$ \\
\hline \multicolumn{4}{|l|}{ Recurrent $\mathrm{MI}<90$ days } \\
\hline Current & $194 / 734$ & $424 / 2057$ & $1.27(1.03-1.57)$ \\
\hline Previous & $63 / 734$ & $195 / 2057$ & $0.86(0.63-1.19)$ \\
\hline Remote & $17 / 734$ & $68 / 2057$ & $0.81(0.46-1.41)$ \\
\hline Death $<90$ days & $71 / 323$ & $188 / 916$ & $0.82(0.57-1.18)$ \\
\hline \multicolumn{4}{|l|}{ Proton pump inhibitor } \\
\hline Pantoprazole & $46 / 734$ & $125 / 2057$ & $1.02(0.70-1.47)$ \\
\hline Other & $148 / 734$ & $299 / 2057$ & $1.40(1.10-1.77)$ \\
\hline $\begin{array}{l}\text { Patients not receiving } \\
\text { clopidogrel }\end{array}$ & $438 / 6277$ & $1300 / 17291$ & $1.02(0.90-1.15)$ \\
\hline Histamine- $\mathrm{H}_{2}$ antagonists & $37 / 734$ & $106 / 2057$ & $0.94(0.63-1.40)$ \\
\hline $\begin{array}{l}\text { Patients with no history } \\
\text { of heart failure }\end{array}$ & $134 / 525$ & $319 / 1638$ & $1.33(1.02-1.72)$ \\
\hline Recurrent $\mathrm{Ml}<1$ year & $240 / 982$ & $497 / 2626$ & $1.23(1.01-1.49)$ \\
\hline Death $<1$ year & $116 / 531$ & $269 / 1407$ & $0.89(0.67-1.18)$ \\
\hline
\end{tabular}

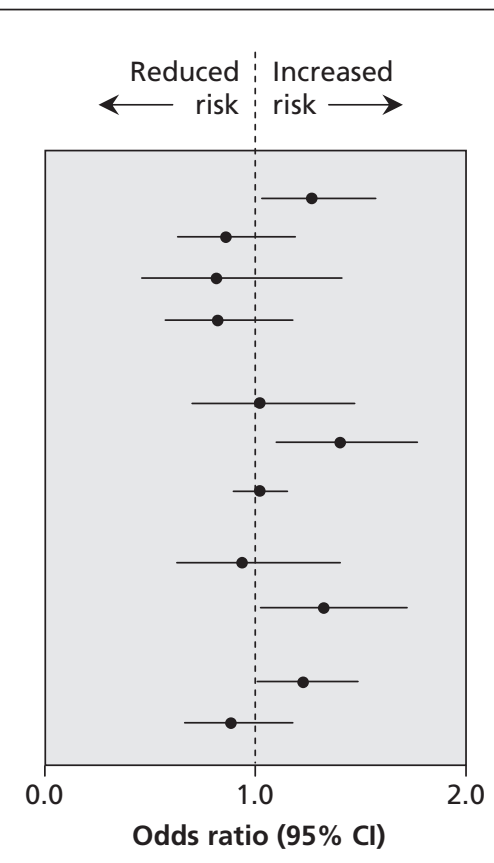

Figure 2: Association between acid-reducing therapies and adverse outcomes. Current use of proton pump inhibitors (within 30 days before the index date) was associated with recurrent infarction within 90 days and 1 year following hospital discharge after treatment of acute myocardial infarction (MI) among patients who were receiving clopidogrel. No such association was apparent with earlier therapy or among patients who were not receiving clopidogrel following acute MI. Treatment with histamine $\mathrm{H}_{2}$-receptor antagonists or pantoprazole, neither of which inhibits cytochrome P450 2C19, was not associated with recurrent infarction, whereas treatment with other proton pump inhibitors (omeprazole, lansoprazole and rabeprazole) was associated with reinfarction. Risk of death was not increased during therapy with proton pump inhibitors. *Data are for current proton pump inhibitor use unless stated otherwise. 
not inhibit cytochrome P450 2C19. ${ }^{13}$ In contrast, compared with no treatment, other proton pump inhibitors were collectively associated with a $40 \%$ increase in the risk of recurrent myocardial infarction within 90 days of hospital discharge (OR 1.40, 95\% CI 1.10-1.77) (Table 2 and Figure 2).

We estimated the attributable risk of concomitant treatment with a cytochrome P450 2C19-inhibiting proton pump inhibitor and clopidogrel, using the point estimate of the adjusted OR (1.40) as an approximation of the relative risk, and with a conservative exposure estimate of 0.2 for any of omeprazole, lansoprazole or rabeprazole. ${ }^{28}$ Among older patients taking clopidogrel following acute myocardial infarction, we estimated that about $7.4 \%$ of readmissions because of reinfarction within 90 days after discharge occurred as the result of concomitant therapy with these agents. Using a less conservative estimate, if $40 \%$ of patients receiving clopidogrel were also prescribed one of these proton pump inhibitors, about $14 \%$ of all readmissions because of reinfarction could be attributed to this drug interaction.

\section{Interpretation}

In this population-based study spanning almost 6 years, we found that, among older patients taking clopidogrel following acute myocardial infarction, concomitant use of a proton pump inhibitor was associated with a significantly increased shortterm risk of reinfarction. Depending on the prevalence of exposure to these drugs, we estimate that $5 \%$ to $15 \%$ of early readmissions because of myocardial infarction among patients taking clopidogrel could be the result of this drug interaction. In contrast, we found no association with more remote use of a proton pump inhibitor or current use of histamine $\mathrm{H}_{2}$-receptor antagonists. As predicted from its basic pharmacology, pantoprazole displayed no such association in a stratified analysis, whereas other proton pump inhibitors did. In sum, these observations support the hypothesis that some proton pump inhibitors significantly reduce or even abolish the cardioprotective effects of clopidogrel. Indeed, the increase in absolute risk of myocardial infarction during proton pump inhibitor therapy in this study approximated the $2.1 \%$ absolute risk reduction conferred by clopidogrel in the Clopidogrel in Unstable Angina to Prevent Recurrent Ischemic Events (CURE) study. ${ }^{1}$

Our findings have major implications for public health, given the number of patients exposed to this drug interaction. With annual sales of US $\$ 7.3$ billion in $2007,{ }^{29}$ clopidogrel is the drug with the second-largest sales volume worldwide. Millions of patients around the world receive a coronary stent or experience new or recurrent myocardial infarction each year. The majority of them will be prescribed clopidogrel in addition to ASA. Recent guidelines published by the American Heart Association, the American College of Gastroenterology and the American College of Cardiology advocate proton pump inhibitor therapy for the majority of patients receiving ASA after myocardial infarction, including all patients aged 60 years or older. ${ }^{17}$ Our findings suggest that indiscriminate treatment with a proton pump inhibitor could result in thousands of additional cases of recurrent myocardial infarction each year, all of which could potentially be avoided by preferentially using pantoprazole in patients taking clopidogrel who require treatment with a proton pump inhibitor.

\section{Limitations}

Some limitations of our research merit emphasis. We had no data on important cardiac risk factors such as smoking status, blood pressure and lipoproteins. Importantly, because our data sets included only drugs listed on the provincial formulary, we could not identify use of nonprescription medications, particularly over-the-counter ASA. Although we matched cases and controls on important predictors of outcome, some imbalance was evident in their measured characteristics (Table 1). However, this observation is expected and does not threaten our primary conclusion, because we found no association between proton pump inhibitor

Table 2: Association between exposure to proton pump inhibitors and recurrent myocardial infarction among patients who started taking clopidogrel following index myocardial infarction

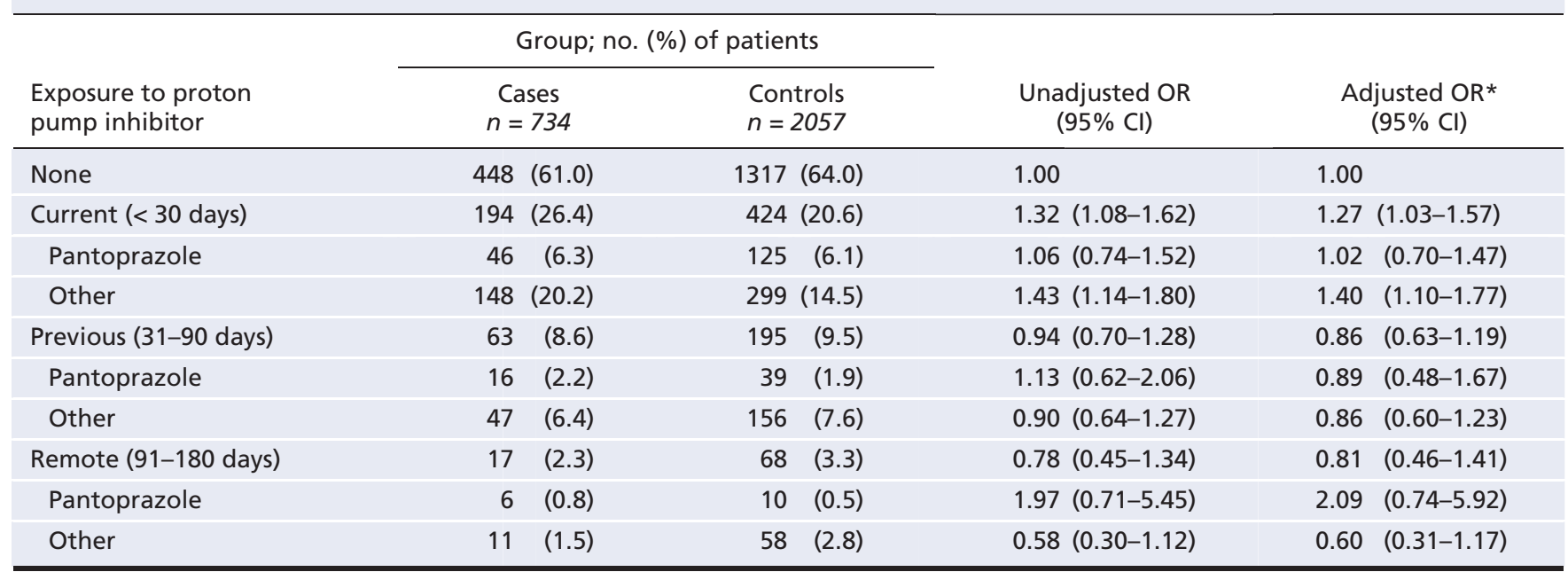

Note: $\mathrm{Cl}=$ confidence interval, $\mathrm{OR}=$ odds ratio.

*Adjusted for age, sex, income quintile estimated from residential postal code, Charlson comorbidity index, length of stay in hospital during the index admission for acute myocardial infarction, 9 medical conditions previously shown to correlate with short-term mortality following acute myocardial infarction and identified at the index hospital admission (diabetes with complications, dysrhythmias, pulmonary edema, cardiogenic shock, acute renal insufficiency, chronic renal insufficiency, congestive heart failure and cerebrovascular disease), and use of medications listed in Appendix 1 (www.cmaj.ca/cgi/content/full/cmaj.082001/DC1). 
therapy and reinfarction in several sensitivity analyses, including an analysis of patients not receiving clopidogrel. Miscoding is a potential threat to the validity of any observational study, but previous validation studies have indicated that coding for acute myocardial infarction in Ontario's administrative databases is very good. ${ }^{30,31}$ Finally, because some patients take proton pump inhibitors intermittently, misclassification of exposure status is possible. However, with our study design, such misclassification would likely attenuate estimates of effect.

\section{Conclusion}

In summary, we found that, among patients taking clopidogrel following acute myocardial infarction, the concomitant use of a proton pump inhibitor that inhibits cytochrome P450 2C19 (omeprazole, lansoprazole or rabeprazole) was associated with an increased risk of recurrent myocardial infarction. This effect, which was not seen with pantoprazole therapy, presumably reflects inhibition of the metabolic bioactivation of clopidogrel. Our findings highlight a widely unappreciated, common and completely avoidable drug interaction in a population at high risk of recurrent coronary events. Pending further data regarding the clinical significance of drug interactions with clopidogrel, we believe that concomitant treatment with clopidogrel and proton pump inhibitors other than pantoprazole should be minimized when possible. Ranitidine or another $\mathrm{H}_{2}$-receptor antagonist may be an appropriate alternative for patients who require acid-lowering therapy. If a proton pump inhibitor is required, pantoprazole should be used preferentially in patients who are also receiving clopidogrel.

\section{This article has been peer reviewed.}

Competing interests: Muhammad Mamdani was employed at Pfizer Global Pharmaceuticals from January 2006 to March 2007. No competing interests declared by David Juurlink, Tara Gomes, Dennis Ko, Paul Szmitko, Peter Austin, Jack Tu, David Henry or Alex Kopp.

Contributors: All of the authors contributed to the conception and design of the study. Tara Gomes and Alex Kopp collected the data, and all of the authors contributed to the analysis and interpretation of the data. David Juurlink drafted the article. All of the authors revised it critically for important intellectual content and approved the final version submitted for publication.

Acknowledgements: We thank Donald Redelmeier for comments on an earlier draft of this manuscript, John Iazzetta for helpful comments and Ashif Kachra for assistance with manuscript preparation.

Funding: This study was supported by the Ontario Ministry of Health and Long-Term Care, the Canadian Institutes of Health Research (CIHR) and a CIHR Team Grant in Cardiovascular Outcomes Research. David Juurlink was supported by a New Investigator Award from the CIHR. Dennis Ko was supported by a Clinician Scientist Award from the Heart and Stroke Foundation of Ontario. Peter Austin was supported by a Career Investigator Award from the Heart and Stroke Foundation of Ontario. Jack Tu was supported by a Canada Research Chair in Health Services Research and a Career Investigator Award from the Heart and Stroke Foundation of Ontario. The opinions, results and conclusions are those of the authors. No endorsement by the Ontario Ministry of Health and Long-Term Care or by the Institute for Clinical Evaluative Sciences is intended or should be inferred.

\section{REFERENCES}

1. Yusuf S, Zhao F, Mehta SR, et al. Effects of clopidogrel in addition to aspirin in patients with acute coronary syndromes without ST-segment elevation. $N$ Engl J Med 2001;345:494-502.
2. Ackman ML, Graham MM, Hui C, et al. Effect of a prior authorization process on antiplatelet therapy and outcomes in patients prescribed clopidogrel following coronary stenting. Can J Cardiol 2006;22:1205-8.

3. Ho PM, Peterson ED, Wang L, et al. Incidence of death and acute myocardial infarction associated with stopping clopidogrel after acute coronary syndrome. JAMA 2008;299:532-9.

4. Sheehy O, LeLorier J, Rinfret S. Restrictive access to clopidogrel and mortality following coronary stent implantation. CMAJ 2008;178:413-20.

5. Jackevicius CA, Tu JV, Demers V, et al. Cardiovascular outcomes after a change in prescription policy for clopidogrel. N Engl J Med 2008;359:1802-10.

6. Savi P, Pereillo JM, Uzabiaga MF, et al. Identification and biological activity of the active metabolite of clopidogrel. Thromb Haemost 2000;84:891-6.

7. Savi P, Herbert JM, Pflieger AM, et al. Importance of hepatic metabolism in the antiaggregating activity of the thienopyridine clopidogrel. Biochem Pharmacol 1992;44:527-32.

8. Kim KA, Park PW, Hong SJ, et al. The effect of CYP2C19 polymorphism on the pharmacokinetics and pharmacodynamics of clopidogrel: a possible mechanism for clopidogrel resistance. Clin Pharmacol Ther 2008;84:236-42.

9. Simon T, Verstuyft C, Mary-Krause M, et al. Genetic determinants of response to clopidogrel and cardiovascular events. N Engl J Med 2009;360:363-75.

10. Mega JL, Close SL, Wiviott SD, et al. Cytochrome P-450 polymorphisms and response to clopidogrel. N Engl J Med 2009;360:354-62.

11. Proton pump inhibitors. Ottawa (ON): Canadian Agency for Drugs and Technologies in Health; 2008. Available: www.cadth.ca/index.php/en/compus/current-topics /ppis (accessed 2008 Dec. 9).

12. Small DS, Farid NA, Payne CD, et al. Effects of the proton pump inhibitor lansoprazole on the pharmacokinetics and pharmacodynamics of prasugrel and clopidogrel. J Clin Pharmacol 2008;48:475-84.

13. Li XQ, Andersson TB, Ahlstrom M, et al. Comparison of inhibitory effects of the proton pump-inhibiting drugs omeprazole, esomeprazole, lansoprazole, pantoprazole, and rabeprazole on human cytochrome P450 activities. Drug Metab Dispos 2004;32:821-7.

14. Gilard M, Arnaud B, Cornily JC, et al. Influence of omeprazole on the antiplatelet action of clopidogrel associated with aspirin: the randomized, double-blind OCLA (Omeprazole CLopidogrel Aspirin) study. J Am Coll Cardiol 2008;51:256-60.

15. Aubert RE, Epstein RS, Teagarden JR, et al. Abstract 3998: Proton pump inhibitors effect on clopidogrel effectiveness: the Clopidogrel Medco Outcomes Study. Circulation 2008;118:S_815.

16. Pezalla E, Day D, Pulliadath I. Initial assessment of clinical impact of a drug interaction between clopidogrel and proton pump inhibitors. J Am Coll Cardiol 2008;52:1038-9.

17. Bhatt DL, Scheiman J, Abraham NS, et al. ACCF/ACG/AHA 2008 expert consensus document on reducing the gastrointestinal risks of antiplatelet therapy and NSAID use: a report of the American College of Cardiology Foundation Task Force on Clinical Expert Consensus Documents. Circulation 2008;118:1894-909.

18. Juurlink DN, Mamdani MM, Lee DS, et al. Rates of hyperkalemia after publication of the Randomized Aldactone Evaluation Study. N Engl J Med 2004:351:543-51.

19. Mamdani M, Rochon P, Juurlink DN, et al. Effect of selective cyclooxygenase 2 inhibitors and naproxen on short-term risk of acute myocardial infarction in the elderly. Arch Intern Med 2003;163:481-6.

20. Park-Wyllie LY, Juurlink DN, Kopp A, et al. Outpatient gatifloxacin therapy and dysglycemia in older adults. N Engl J Med 2006;354:1352-61.

21. Battistella M, Mamdami MM, Juurlink DN, et al. Risk of upper gastrointestinal hemorrhage in warfarin users treated with nonselective NSAIDs or COX-2 inhibitors. Arch Intern Med 2005;165:189-92.

22. Juurlink DN, Mamdani MM, Kopp A, et al. Drug-induced lithium toxicity in the elderly: a population-based study. J Am Geriatr Soc 2004;52:794-8.

23. Juurlink DN, Mamdani M, Kopp A, et al. Drug-drug interactions among elderly patients hospitalized for drug toxicity. JAMA 2003;289:1652-8.

24. Robins JM, Gail MH, Lubin JH. More on "Biased selection of controls for casecontrol analyses of cohort studies." Biometrics 1986;42:293-9.

25. Tu JV, Austin PC, Walld R, et al. Development and validation of the Ontario acute myocardial infarction mortality prediction rules. J Am Coll Cardiol 2001;37:992-7.

26. Charlson ME, Pompei P, Ales KL, et al. A new method of classifying prognostic comorbidity in longitudinal studies: development and validation. J Chronic Dis 1987;40:373-83.

27. Lau WC, Gurbel PA, Watkins PB, et al. Contribution of hepatic cytochrome P450 $3 \mathrm{~A} 4$ metabolic activity to the phenomenon of clopidogrel resistance. Circulation 2004;109:166-71.

28. Rockhill B, Newman B, Weinberg C. Use and misuse of population attributable fractions. Am J Public Health 1998;88:15-9.

29. Top ten global products - 2007. IMS Midas Monthly. London (UK): IMS Health Inc.; December 2007. Available: www.imshealth.com/deployedfiles/imshealth/Global /Content/StaticFile/Top_Line_Data/Top10GlobalProducts.pdf (accessed 2009 Jan. 27).

30. Austin PC, Daly PA, Tu JV. A multicenter study of the coding accuracy of hospital discharge administrative data for patients admitted to cardiac care units in Ontario. Am Heart J 2002;144:290-6.

31. Lee DS, Donovan L, Austin PC, et al. Comparison of coding of heart failure and comorbidities in administrative and clinical data for use in outcomes research. Med Care 2005;43:182-8.

Correspondence to: Dr. David Juurlink, G Wing 106, Sunnybrook

Health Sciences Centre, 2075 Bayview Ave., Toronto ON

M4N 3M5; fax 416 480-6048; dnj@ices.on.ca 